\title{
A DETERMINING FACTOR OF RETROACTIVE INHIBITION $^{1}$
}

\author{
CHIZUKO OKI ${ }^{2}$ \\ University of Tokyo
}

\begin{abstract}
Determining factors of retroactive inhibition were analysed by paired-associate method, in which stimulus members were the same but response members were varied. Experimental design was so improved that intra-list effect was kept constant among lists. 10 graduate students in psychology served as $S$ s. Similarity between response members was determined by the method of multidimensional scaling. The amounts of retroactive inhibition had linear relationship with one of analysed dimensions. The dimension could successfully be used in predicting several critical cases.
\end{abstract}

Retroactive inhibition (RI) has been considered as a function of similarity between original learning (OL) and interpolated learning (IL) lists. Osgood (1946, 1948, 1949) used paired-associate method, defining the similarity of response members of items (or paired-associates) by the similarity of meaning among adjectives. A stimulus member consisted of a letterpair (for example c.m. or f.s.) was associated with two different adjectives. One of the letter-pairs was included in OL list, and the other was included in IL list. OL- and IL-list were so constructed that each of the stimulus members was always paired with adjectives of a certain degree of similarity. Three conditions of the

1 The first part of this paper (Exp. I) is based on a dissertation submitted in partial fulfilment of the requirements for BA at Tokyo Woman's Christian College, and the remaining part of this paper is a part of a dissertation presented to the faculty of the University of Tokyo in partial fulfillment of requirements for the MA degree.

2 The author is grateful to Professor Yoshihisa Tanaka at the University of Tokyo for many valuable criticisms and for the suggestion of using the method of multidimensional scaling. She is indebted to Professor Moriji Sagara at the University of Tokyo (now at Tokyo Woman's Christian College) and to Professor Tamotsu Fujinaga at Tokyo Woman's Christian College for many valuable advices. meaning relations were used (similar, neutral and opposed) and retroacting effects were compared.

There arise some doubts on the method used by Osgood as well as by Gibson (1941). First of all, similarity between lists in their studies was defined by similarity between corresponding response members, with which the same stimulus member was associated in OL- and ILlist. Retroacting effect can be treated in terms of the inter-list effect as well as the intra-list effect. Suppose that similarity exists between response members in OLand IL-list, (we will call it inter-member similarity), then retroacting effect would occur among them. Suppose some response members within a list are similar, confusion and competition may occur among these members which would have inhibitory effect on the retention of members of the list. The possible effects of these intra-list and inter-member similarities (that of between corresponding response members) were assumed to be constant in these studies. Similarity between OL- and IL-list does not necessarily coincide with the similarity between corresponding members. The effect of similarity between OL- and IL-list on RI cannot always be substituted by the effect of similarity between corresponding members. It is doubtful that the amount of 
RI between the lists in these studies is a function of similarity between lists which is defined by the similarity between the response members.

There remains a problem whether it is permissible to substitute the relationship between lists by the relation between corresponding response members. A new design is needed for measuring the effects of the relation between materials on RI.

A group of nonsense geometrical figures was selected as response members. Each figure consisted of twelve contour circles as is shown in Fig. 1. A grey patch was attached to one of circles. All the figures consisted of the same contour but differed in the position of the patch.

Therefore $S$ could identify a figure by the position of the patch. Relationship between response members was represented by the distance between patches of figures. We defined the distance between patches by the smallest central angle, as will be explained later.

Let us measure RI under the condition of the same distance, according to the Osgood's paradigm, in order to show whether the relationship between corresponding response members represents the relationship between lists.

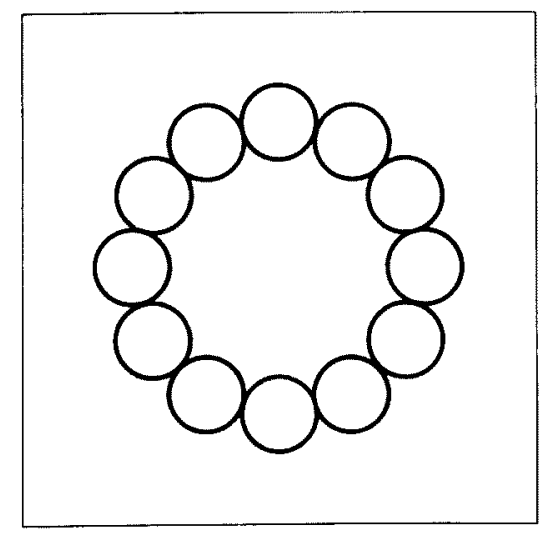

Fig. 1. One of 12 small circles is filled by a grey discus. These positions are named from No. 1. to No. 12. after the dial of a clock.

\section{EXPERIMENT I}

\section{Method}

Materials. A list to be learned consisted of 4 items ( 4 paired-associates), made of 4 nonsense syllables for stimulus members and 4 geometrical figures for response members. Stimulus members in OL and IL were the same, but response members differed. The nonsense syllables used were NUNA., REKE, SEHO, and YURO in Japanese letters (katakana). Each syllable was printed with black ink on a white square cardboard, $15 \times 15 \mathrm{~cm}$ in size.

Nonsense geometrical figures for response members are shown in Fig. 1. The diameter of the large circle, which consisted of 12 small circles, was $8.5 \mathrm{~cm}$. Twelve contours were drawn in black ink and one of the contours was filled with a grey discus (value 14). Twelve figures can be used varying the position of the grey discus in the figure. These figures were named after the dial of a clock from No. 1. to No. 12. Inter-member relationship was represented by the distance between grey disci of response figures on the large circle. The distance was defined by the smallest central angle formed by two straight lines passing the center of the large circle and the center of each discus. We chose $30^{\circ}$ as an arbitrary unit of distance. Therefore the distance between No. 2. and No. 4. was 2 units.

Procedure. Six distances can be used owing to the definition of the distance. Twentyfour response pairs can be made for each distance. Suppose No. 1. is chosen as the response member in OL list under 1 unit distance condition, then, No. 2. and No. 12. can be used as response members in IL list. Two figures can be used in IL per figure in OL which has 12 possible choices. Therefore the total number of possible pairs is 24 in a certain distance condition. For economy of time and labor, we selected one from the possible two pairs for IL. So we had 12 pairs in a certain distance. As the numbers of nonsense syllables was 4 , the 12 pairs were arbitrarily divided into 3 sub-groups. Let us call subgroups as sub-conditions. The control experi- 
TABLE 1

Experimental design used in Exp. I

\begin{tabular}{|c|c|c|c|c|c|c|c|}
\hline \multirow{2}{*}{$\begin{array}{c}\text { Distance } \\
\text { between } \\
\text { disci }\end{array}$} & \multirow{2}{*}{$\begin{array}{c}\text { Syllable } \\
\text { for } \\
\text { stimulus } \\
\text { member }\end{array}$} & \multicolumn{6}{|c|}{$\begin{array}{l}\text { Figures for response } \\
\text { members }\end{array}$} \\
\hline & & $\mathrm{OL}^{A}$ & IL & $\mathrm{OL}$ & IL & $\mathrm{OL}^{\mathrm{C}}$ & IL \\
\hline \multirow{4}{*}{1} & NUNA & 6 & 5 & 9 & 10 & 2 & 1 \\
\hline & REKE & 1 & 2 & 5 & 6 & 4 & 3 \\
\hline & SEHO & 8 & 7 & 12 & 11 & 10 & 9 \\
\hline & YURO & 3 & 4 & 7 & 8 & 11 & 12 \\
\hline \multirow{4}{*}{2} & NUNA & 11 & 9 & 9 & 7 & 2 & 4 \\
\hline & REKE & 3 & 1 & 5 & 3 & 10 & 12 \\
\hline & SEHO & 8 & 10 & 12 & 2 & 7 & 5 \\
\hline & YURO & 4 & 6 & 6 & 8 & 1 & 11 \\
\hline \multirow{4}{*}{3} & NUNA & 3 & 6 & 2 & 11 & 1 & 4 \\
\hline & REKE & 7 & 10 & 10 & 7 & 6 & 3 \\
\hline & SEHO & 5 & 8 & 12 & 9 & 11 & 2 \\
\hline & YURO & 4 & 1 & 8 & 5 & 9 & 12 \\
\hline \multirow{4}{*}{4} & NUNA & 2 & 6 & 12 & 4 & 10 & 2 \\
\hline & REKE & 9 & 5 & 11 & 7 & 8 & 12 \\
\hline & SEHO & 3 & 11 & 6 & 10 & 7 & 3 \\
\hline & YURO & 4 & 8 & 5 & 1 & 1 & 9 \\
\hline \multirow{4}{*}{5} & NUNA & 8 & 3 & 11 & 4 & 1 & 6 \\
\hline & REKE & 2 & 9 & 6 & 1 & 10 & 5 \\
\hline & SEHO & 4 & 11 & 7 & 12 & 9 & 2 \\
\hline & YURO & 5 & 10 & 3 & 8 & 12 & 7 \\
\hline \multirow{4}{*}{6} & NUNA & 11 & 5 & 1 & 7 & 9 & 3 \\
\hline & REKE & 12 & 6 & 3 & 9 & 7 & 1 \\
\hline & SEHO & 2 & 8 & 6 & 12 & 4 & 10 \\
\hline & YURO & 10 & 4 & 8 & 2 & 5 & 11 \\
\hline \multirow{4}{*}{ Control } & NUNA & 5 & - & 6 & - & 3 & - \\
\hline & REKE & 12 & - & 8 & - & 1 & - \\
\hline & SEHO & 4 & - & 11 & - & 9 & - \\
\hline & YURO & 7 & - & 2 & - & 10 & - \\
\hline
\end{tabular}

ment without $I L$ was added, which was divided into 3 sub-conditions. The experimental design used is shown in Table 1.

A total of $84 S$ s were used ( $72 S$ s for 6 distances, and $12 \mathrm{Ss}$ for the control condition), as $4 S$ s served in a sub-condition.

A nonsense syllable (stimulus member) was presented for $2 \mathrm{sec}$. As soon as the stimulus member was removed, a geometrical figure (response member) was presented for 2 sec. $S$ was instructed to memorize members of the items (paired-associates). $S$ was requested to learn all of the 4 paired-associates in a list. $S$ was requested to predict the position of the discus of response figure from the second trial, as soon as the stimulus member was presented. Then, the response member was presented after $S$ responded to the stimulus member.

Items in the list were presented in the randomized order which was changed from trial to trial. $S$ had to learn the OL list 4 times. Five $\min$ rest was given when $\mathrm{OL}$ was over. $S$ was required to learn the IL list 4 times. Five min rest was given when IL was over. In relearning (RL), $S$ was requested to learn the OL list until he reached the criterion that he could successfully predict all of the 4 response figures successively twice. $S$ learned $O L$ list 4 times, in the control experiment, and rest interval was $12 \mathrm{~min}$.

Subjects. The subjects were 84 freshmen at Tokyo Woman's Christian College.

\section{Results}

The index of RI used was the total number of incorrect responses (errors) in RL. The number of errors in all of the sub-conditions, is shown in Table 2. Amounts of RI differed among the 3 sub-conditions, in spite of the equality of distances between disci on response members. The amounts of $\mathrm{RI}$ in 1 unit distance condition were 20 , 34 and 65 , these of 2 unit were 30,31 and 52 , these of 3 unit were 31,38 and 49 , these of 4 unit were 27,46 and 57 , these of 5 unit were 36,54 and 64 , and these of 6 unit were 19, 28 and 58. Numbers of errors in the control experiment were 2 in all of the 3 sub-conditions. We can conclude that RI exsists for all experimental conditions compared with the control experiment.

If we sum up all the errors of (3 subconditions) 12 pairs in a definite distance, the amount of RI in the condition of 1 unit distance was 119 , it was 113 in 2 unit distance, 118 in 3 unit distance, 130 in 4 unit distance, 154 in 5 unit distance, and 
TABLE 2

$\mathrm{RI}$, errors in $\mathrm{RL} \dagger$

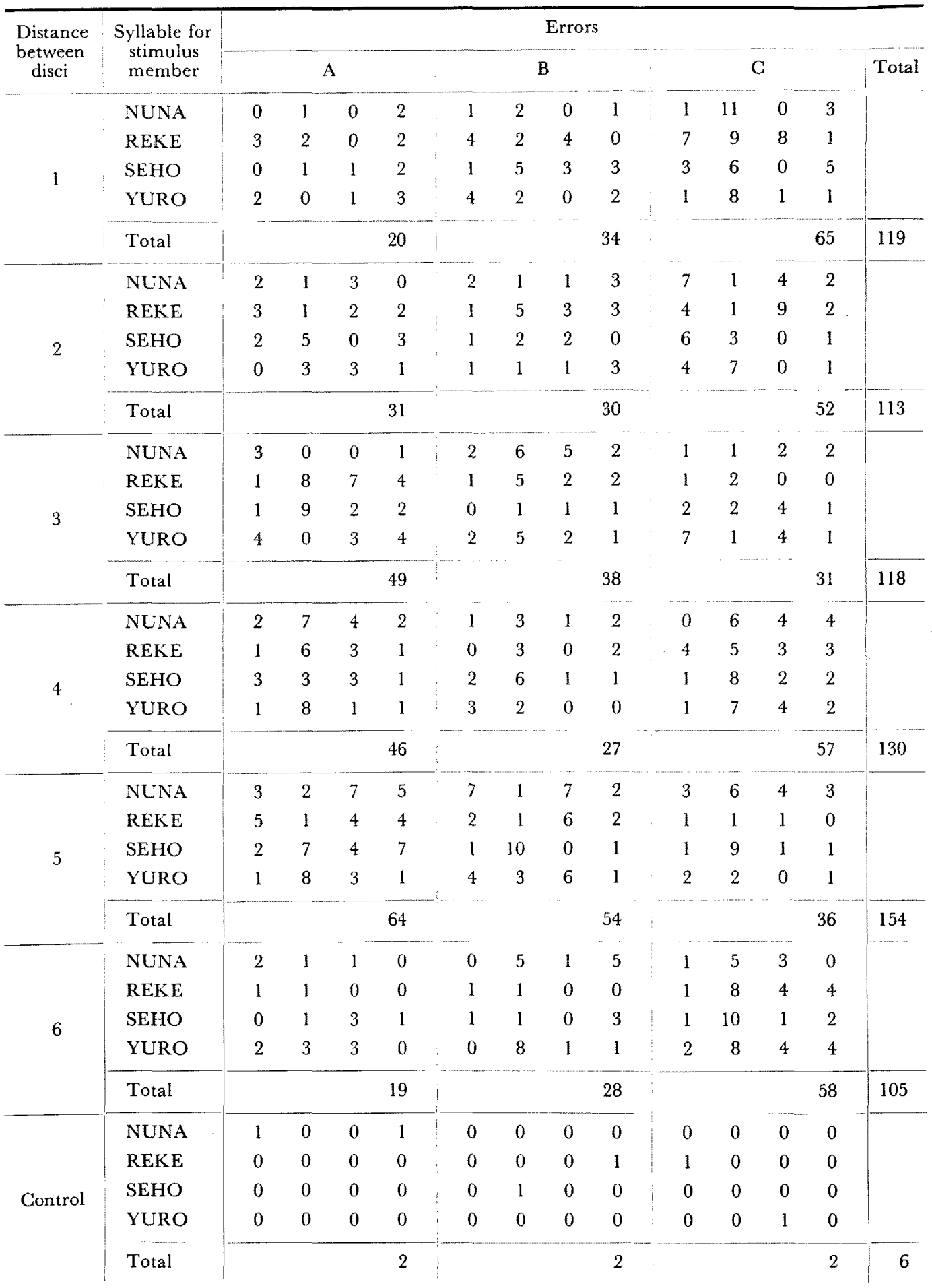

† This experiment was carried out according to Table 1. 
was 105 in 6 unit distance. The results are shown in Fig. 2. The amount of RI is largest at $\mathbf{5}$ unit distance, it is smallest at 6 unit distance, and the amounts are almost equal for the remaining cases. The amount of RI does not show linear relationship with the distance between disci on response figures.

The differences between amounts of RI in 3 sub-conditions were large in spite of the equality of the distances between disci. The reason of differences may due to the fact that response members (in both $\mathrm{OL}$ and IL) vary for all 3 sub-conditions. Intra-list effect should be kept constant, in order to detect determining factors of RI.

We assume that the total amount of 3 sub-conditions represents $\mathrm{RI}$ in a certain

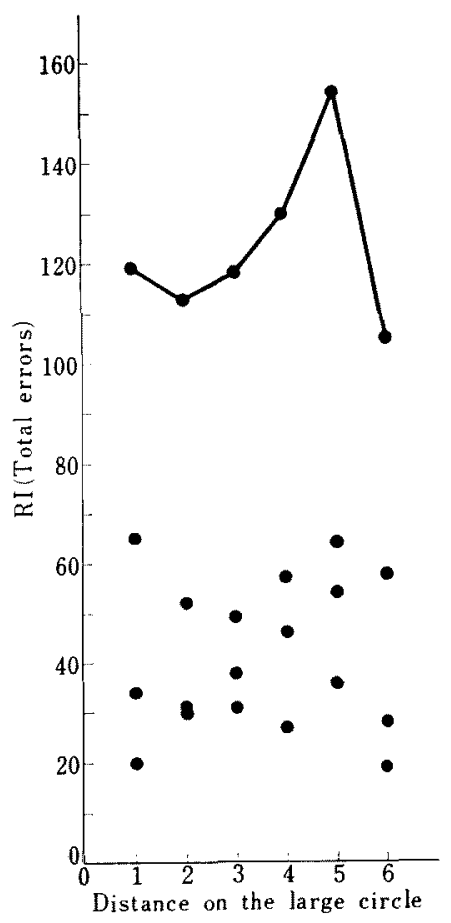

FIG. 2. RI, in the condition of various distance between disci. $+\uparrow$

$\uparrow$ A solid circle represents RI per sub-condition, of $4 S$ s.

$+\dagger$ The line represents RI as total errors of $12 \mathrm{~S}$ s in the condition of the distance. distance condition, although each amount of 3 sub-conditions does not represent RI in a certain distance condition. We can conclude that RI is not linearly related to the distance between disci, as can be seen in Fig. 2.

We must find some factors which are linearly related to the amount of RI. First, it is necessary that the amount of RI is measured for a certain pair of response members. For the purpose of measurement of RI per pair, we have to improve experimental design, so that we can hold intra-list effect constant. Secondly, we will examine whether the amount of RI varies with variation of corresponding response members.

\section{EXPERIMENT II}

\section{Method}

Materials. A list to be learned consisted of 6 items made of 6 colors for the stimulus members and 6 geometrical figures for response members. Stimulus members should be simple and should not easily be confused with response members. Colors used were red (R), orange $(\mathrm{O})$, yellow $(\mathrm{Y})$, green $(\mathrm{G})$, blue $(\mathrm{B})$ and violet $(\mathrm{V})$ selected from the Guide to Color Standard (1954) of Japan Color Research Institute. Their hues, values and chromas are shown in Table 3 . Colored discus $2.2 \mathrm{~cm}$ in diameter was put at the center of a white cardboard, $15 \times 15 \mathrm{~cm}$ in size. Geometrical figures for response members were selected from 12 figures used in Exp. I.

Experimental item was consisted of yellow

TABle 3

Colors used in Exp. II

\begin{tabular}{l|rcc}
\hline \multicolumn{1}{c|}{ Color } & Hue & Value & Chroma \\
\hline Red (R) & 1 & 14 & 10 \\
Orange (O) & 4 & 17 & 7 \\
Yellow (Y) & 8 & 19 & 6 \\
Green (G) & 12 & 16 & 6 \\
Blue (B) & 16 & 14 & 6 \\
Violet (V) & 21 & 13 & 5
\end{tabular}


(Y) stimulus combined with a response member selected from the figures of No. 1, 3, 6, 7, and 10. The sets ${ }^{3}$ in the OL- and IL-list are shown in Table 4. Let us call the paired-associate with yellow stimulus, $Y$ item. Five sets of $Y$ items (which consisted of 2 items, one in OL and another in IL) were prepared for Exp. II as are shown in Table 4.

Besides the experimental item ( $\mathrm{Y}$ item), 5 other items were used for the blank experiments, so that 6 items were included in a list.
TABLE 4

The sets of $\mathrm{Y}$ items

\begin{tabular}{c|rc}
\hline \multirow{2}{*}{ Set of Y items } & \multicolumn{3}{|c}{ Response figures associated } \\
& OL & with Y \\
\hline A & 7 & 1 \\
B & 10 & 6 \\
C & 6 & 7 \\
D & 1 & 3 \\
E & 3 & 10 \\
\hline
\end{tabular}

TABLE 5

The blocks of lists for the blank experiments in $\mathrm{OL}$ and $\mathrm{IL} \dagger+\dagger$

\begin{tabular}{|c|c|c|c|c|c|c|c|c|c|c|}
\hline \multirow{4}{*}{$\begin{array}{l}\text { Color for } \\
\text { stimulus } \\
\text { member }\end{array}$} & \multicolumn{10}{|c|}{ Figures for response members } \\
\hline & \multicolumn{10}{|c|}{ Block for the blank experiments } \\
\hline & \multicolumn{2}{|c|}{$\alpha$} & \multicolumn{2}{|c|}{$\beta$} & \multicolumn{2}{|c|}{$\gamma$} & \multicolumn{2}{|c|}{$\hat{o}$} & \multicolumn{2}{|c|}{$\varepsilon$} \\
\hline & $\mathrm{OL}$ & IL & OL & IL & OL & IL & OL & IL & OL & IL \\
\hline $\mathrm{R}$ & 9 & 2 & 5 & 8 & 11 & 9 & 2 & 5 & 8 & 11 \\
\hline $\mathrm{O}$ & 2 & 8 & 9 & 11 & 5 & 2 & 8 & 9 & 11 & 5 \\
\hline G & 5 & 9 & 11 & 2 & 8 & 5 & 9 & 11 & 2 & 8 \\
\hline $\mathrm{B}$ & 11 & 5 & 8 & 9 & 2 & 11 & 5 & 8 & 9 & 2 \\
\hline V & 8 & 11 & 2 & 5 & 9 & 8 & 11 & 2 & 5 & 9 \\
\hline
\end{tabular}

The purpose of adding other items for the blank experiments was to make the retention of the $Y$ item difficult. If only a set of $Y$ items is presented, $S$ s will retain them so fast and accurately that $\mathrm{RI}$ will not appear. Each one of the remaining colors $(\mathrm{R}, \mathrm{O}, \mathrm{G}, \mathrm{B}$ and $\mathrm{V})$ was associated with 5 different response figures, excluding the one which was used for the experimental items. All of the possible sets of the stimulus and response members for the blank experiments are shown in Table 5.

These blocks ${ }^{4}$ of the blank experiments had been confirmed to have almost equal $\mathrm{RI}$ on $\mathrm{Y}$ items. If these blocks have different effects on memory of $\mathrm{Y}$ items, we cannot compare the

${ }^{3}$ Let us call a pair of paired-associates in OL and IL as a set.

4 Let us call a pair of lists in OL and IL as a block. amounts of RI between $\mathrm{Y}$ items. Preliminary experiments had been carried out in the following ways. Set of $Y-1$ in OL and $Y-7$ in IL were used as the experimental items to measure the effect of other blank items on these items. The experimental items were constant in spite of the change of the blank blocks (from $\alpha$ to $\varepsilon$ ) as is shown in Table 5. Ss used were 10 undergraduate students. The results show that the blank blocks have almost equal effects on RI of the experimental items ( $\mathrm{Y}-1$ and $\mathrm{Y}-7$ ).

Each $S$ learned 6 sets, one experimental set and 5 blank sets, which constituted a block of experiment for a day, in Exp. II. Each $S$ had to serve 5 times as there were 5 experimental sets. If the amount of RI defined by the number of errors of $\mathrm{Y}$ item (number of incorrect responses) in $\mathrm{RL}$ differs from $\mathrm{A}$ - to E-set, we may be able to conclude that these differences are brought about by differences of the sets 
of $\mathrm{Y}$ items (i.e. which one was selected from $\mathrm{A}$ to $\mathrm{E}$ ). Above conclusion is based upon the following consideration. Five blocks of lists for the blank experiments were confirmed to have almost equal intra-list effect. When each of these 5 blocks of the blank lists are added to each of these 5 experimental sets, the difference in intra-list effect (of 6 items) is due to the experimental sets.

Apparatus. The apparatus consisted of two parts. for presentation of stimulus and for response of $S$ (Fig. 3.). There was a square aperture $15 \times 15 \mathrm{~cm}$ in size, stimulus- and response-member were presented through it. The same figure shown in Fig. 1. was used for the response of $S . \quad S$ was requested to select one of small circles and push it by a finger, as soon as stimulus member was presented. The selection by $S$ was indicated by a lamp which was concealed from $S$. As soon as $S$ responded, a response figure was presented, and $S$ was informed whether his selection was correct or not.

Subjects. The subjects were 10 male and female graduate students in psychology at the University of Tokyo. They could completely discriminate colors used in the experiments.

Procedure. The experimental design was a Graeco-Latin square, as is shown in Table 6. Each $S$ served 5 times on different days (time interval was 48 hours), for 5 sets of experimental items. The 5 main effects in the design were as follows; sets of $\mathrm{Y}$ items, blocks for the

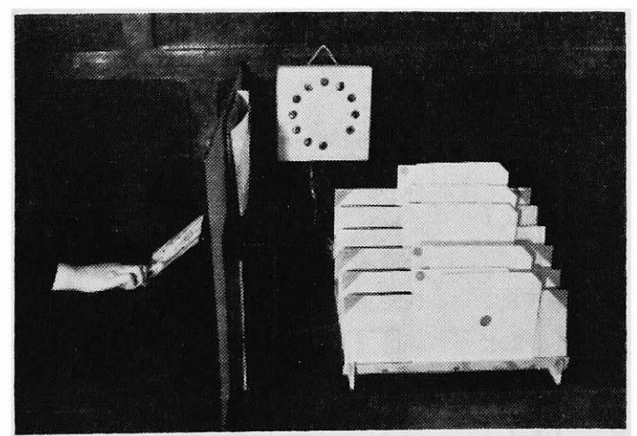

Frg. 3. The sideview of the apparatus. $S$ pushes one of small circles, the lamp at the position is switched on. Cardboards are ready for presentation, on the table.
TABLE 6

The experimental design used in Exp. II ${ }^{\dagger}$

\begin{tabular}{c|rr|ccccc}
\hline \multirow{2}{*}{$\begin{array}{c}\text { Order of } \\
\text { experiments }\end{array}$} & Subjects & \multicolumn{5}{|c}{ Days of experiments } \\
& 1 & 2 & 3 & 4 & 5 \\
I & 1, & 6 & $\mathrm{~B} \varepsilon$ & $\mathrm{C} \alpha$ & $\mathrm{D} \beta$ & $\mathrm{E} \gamma$ & $\mathrm{A} \delta$ \\
II & 2, & 7 & $\mathrm{E} \beta$ & $\mathrm{A} \gamma$ & $\mathrm{B} \delta$ & $\mathrm{C} \varepsilon$ & $\mathrm{D} \alpha$ \\
III & 3, & 8 & $\mathrm{~A} \alpha$ & $\mathrm{B} \beta$ & $\mathrm{C} \gamma$ & $\mathrm{D} \delta$ & $\mathrm{E} \varepsilon$ \\
IV & 4, & 9 & $\mathrm{D} \gamma$ & $\mathrm{E} \delta$ & $\mathrm{A} \varepsilon$ & $\mathrm{B} \alpha$ & $\mathrm{C} \beta$ \\
V & 5, & 10 & $\mathrm{C} \delta$ & $\mathrm{D} \varepsilon$ & $\mathrm{E} \alpha$ & $\mathrm{A} \beta$ & $\mathrm{B} \gamma$
\end{tabular}

† Roman letters represent sets of $\mathrm{Y}$ items and Greek letters represent blocks of lists for the blank experiments.

blank experiments, order of experiments, $S \mathrm{~s}$ and days of experiments (the first, the second, the third, the fourth and fifth day).

$S$ was required to learn OL list until he reached the criterion that he could select all of the 6 selections, correctly at least once. Pairedassociates, which were incorrectly answered, were repeatedly presented in the next trial. $S$ was required to learn IL list, $5 \mathrm{~min}$ after $\mathrm{OL}$ reached the criterion. During the rest interval $E$ continued to talk with him in order to prevent the $S$ from repeating what he had just memorized. The IL was carried in the way as OL, and $S$ learned IL list till he reached the same criterion as OL. There was 5 min's rest interval between IL and RL. The criterion of $\mathrm{RL}$ was one correct repetition.

\section{Results}

The total number of errors of $10 \mathrm{Ss}$ for each condition was used as the index of RI is shown in Table 7. The amount of $\mathrm{RI}$ of the set $\mathrm{A}$ is 14 , that of $\mathrm{B}$ is 6,3 for $\mathrm{C}, 4$ for $\mathrm{D}$, and that of set $\mathrm{E}$ is 8 .

We find that the amount of RI has linear relation to the distance, the smaller the distance, the smaller amount of RI, as is shown in Fig. 4. It seems that the distance between disci on the large circle is a determining factor of RI.

But the result of Exp. I cannot be explained by the factor of distance as is shown in Fig. 2. The contradiction may suggest that there may be some determining fac- 
TABLE 7

RI, number of errors in RLt

\begin{tabular}{|c|c|c|c|c|c|c|c|c|}
\hline \multirow{2}{*}{ Group } & \multirow{2}{*}{$\begin{array}{l}\text { Order of } \\
\text { experiments }\end{array}$} & \multirow{2}{*}{ Subject } & \multicolumn{5}{|c|}{ Days of experiments } & \multirow{2}{*}{ Total } \\
\hline & & & 1 & 2 & 3 & 4 & 5 & \\
\hline \multirow{6}{*}{ I } & I & 1 & 0 & 1 & 0 & 0 & 2 & 3 \\
\hline & II & 2 & 2 & 2 & 1 & 0 & 1 & 6 \\
\hline & III & 3 & 3 & 2 & 0 & 0 & 0 & 5 \\
\hline & IV & 4 & 0 & 0 & 1 & 1 & 0 & 2 \\
\hline & V & 5 & 0 & 0 & 0 & 0 & 0 & 0 \\
\hline & & Total & 5 & 5 & 2 & 1 & 3 & 16 \\
\hline \multirow{6}{*}{2} & I & 6 & 0 & 0 & 1 & 1 & 1 & 3 \\
\hline & II & 7 & 2 & 2 & 1 & 0 & 1 & 6 \\
\hline & III & 8 & 1 & 0 & 2 & 0 & 1 & 4 \\
\hline & IV & 9 & 0 & 1 & 2 & 1 & 0 & 4 \\
\hline & $\mathrm{V}$ & 10 & 0 & 1 & 1 & 0 & 0 & 2 \\
\hline & & Total & 3 & 4 & 7 & 2 & 3 & 19 \\
\hline
\end{tabular}

† This experiment was carried out according to Table 6.

tors other than the distance. The distance in Exp. II may coincide with the factor or a set of factors that determine the amount of RI. The linear relationship between RI and the distance may due to the coincidence of the distance with other determining factor.

Similarity which may be multidimensional has been assumed as a determining factor. We will return to the problem and analyse the similarity of response figures.

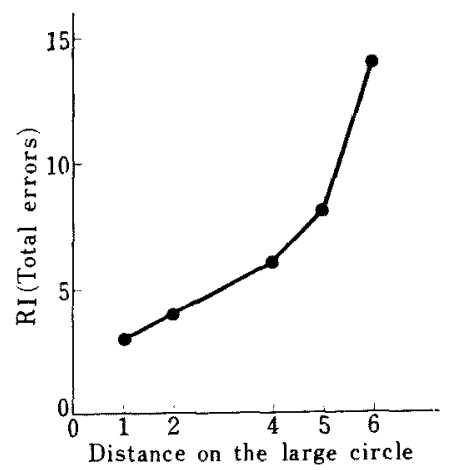

FIG. 4. RI as a function of the distance on the large circle.

\section{EXPERIMENT III}

\section{Method}

Materials. Eight geometrical figures No. 1,3, $4,6,7,8,10$ and 11 were used, which were selected from all possible ones.

Subjects. Ten $S$ s were used, who were the same as Exp. II.

Procedure. The complete method of triads was used for measuring similarity between figures. $S$ was instructed not to judge on the base of a certain attribute of similarity but on base of total impression. Figures were presented to $S$ as are shown in Fig. 5. The 3

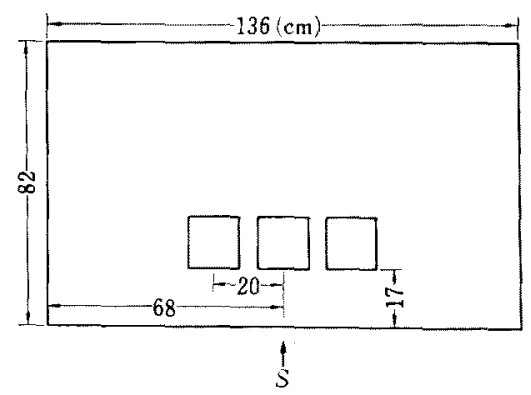

FIG. 5. The situation in which $S$ judged similarity. 
TABLE 8

Mean estimates of similarity ${ }_{k} x_{i j}$ by $10 \mathrm{Ss} . k$ is shown in the first columnt

\begin{tabular}{|c|c|c|c|c|c|c|c|c|c|}
\hline$k$ & $i$ & 1 & 3 & 4 & 6 & 7 & 8 & 10 & 11 \\
\hline \multirow{8}{*}{1} & 1 & & & & & & & & \\
\hline & 3 & & & 1.210 & 1.307 & 0.966 & 1.319 & 1.211 & 0.795 \\
\hline & 4 & & 0.826 & & 1.142 & 1.135 & 1. 105 & 1.085 & 0.683 \\
\hline & 6 & & 0.765 & 0.876 & & 0.801 & 1.007 & 0.883 & 0.688 \\
\hline & 7 & & 1.035 & 0.881 & 1.248 & & 1.290 & 1.065 & 0.595 \\
\hline & 8 & & 0.758 & 0.905 & 0.993 & 0.775 & & 0.756 & 0.522 \\
\hline & 10 & & 0.826 & 0.922 & 1.133 & 0.939 & 1.323 & & 0.690 \\
\hline & 11 & & 1.258 & 1.464 & 1.453 & 1.682 & 1.915 & 1.449 & \\
\hline \multirow{8}{*}{3} & 1 & & & 0.745 & 0.784 & 1.389 & 1.239 & 1.390 & 1.316 \\
\hline & 3 & & & & & & & & \\
\hline & 4 & 1.342 & & & 1.530 & 1.724 & 1.575 & 1.603 & 1.534 \\
\hline & 6 & 1.275 & & 0.654 & & 1.374 & 1.245 & 1.391 & 1.395 \\
\hline & 7 & 0.720 & & 0.580 & 0.728 & & 0.975 & 1.005 & 1.064 \\
\hline & 8 & 0.807 & & 0.635 & 0.803 & 1.026 & & 0.995 & 1.026 \\
\hline & 10 & 0.718 & & 0.624 & 0.719 & 0.995 & 1.005 & & 1.043 \\
\hline & 11 & 0.760 & & 0.652 & 0.717 & 0.940 & 0.975 & 0.959 & \\
\hline \multirow{8}{*}{4} & 1 & & 0.660 & & 0.873 & 0.990 & 0.808 & 1.210 & 1.297 \\
\hline & 3 & 1.515 & & & 1.361 & 1.920 & 1.200 & 1.311 & 1.513 \\
\hline & 4 & & & & & & & & \\
\hline & 6 & 1.145 & 0.735 & & & 1.222 & 1.122 & 1.337 & 1.455 \\
\hline & 7 & 1.010 & 0.521 & & 0.818 & & 0.952 & 0.941 & 1.156 \\
\hline & 8 & 1.238 & 0.833 & & 0.891 & 1.050 & & 1.312 & 1.383 \\
\hline & 10 & 0.826 & 0.763 & & 0.748 & 1.063 & 0.762 & & 1.290 \\
\hline & 11 & 0.771 & 0.661 & & 0.687 & 0.865 & 0.723 & 0.775 & \\
\hline \multirow{8}{*}{6} & 1 & & 0.719 & 0.750 & & 0.570 & 0.580 & 1.140 & 1.000 \\
\hline & 3 & 1.390 & & 0.909 & & 0.629 & 1.015 & 1.408 & 1.422 \\
\hline & 4 & 1.333 & 1.100 & & & 0.658 & 1.000 & 1.447 & 1.555 \\
\hline & 6 & & & & & & & & \\
\hline & 7 & 1.754 & 1.590 & 1.520 & & & 1.433 & 1.653 & 2.120 \\
\hline & 8 & 1.725 & 0.985 & 1.000 & & 0.698 & & 1.383 & 1.294 \\
\hline & 10 & 0.877 & 0.710 & 0.691 & & 0.605 & 0.723 & & 1.022 \\
\hline & 11 & 1.000 & 0.703 & 0.643 & & 0.472 & 0.773 & 0.978 & \\
\hline \multirow{8}{*}{7} & 1 & & 1.172 & 1.048 & 0.529 & & 0.464 & 1.075 & 0.993 \\
\hline & 3 & 0.853 & & 0.855 & 0.445 & & 0.531 & 0.848 & 0.806 \\
\hline & 4 & 0.954 & 1.170 & & 0.556 & & 0.501 & 1.270 & 0.826 \\
\hline & 6 & 1.890 & 2.245 & 1.800 & & & 0.946 & 1.493 & 1.166 \\
\hline & 7 & & & & & & & & \\
\hline & 8 & 2.155 & 1.883 & 1.995 & 1.057 & & & 1.631 & 2.130 \\
\hline & 10 & 0.930 & 1.179 & 0.787 & 0.670 & & 0.613 & & 1.000 \\
\hline & 11 & 1.007 & 1.240 & 1.210 & 0.858 & & 0.469 & 1.000 & \\
\hline
\end{tabular}




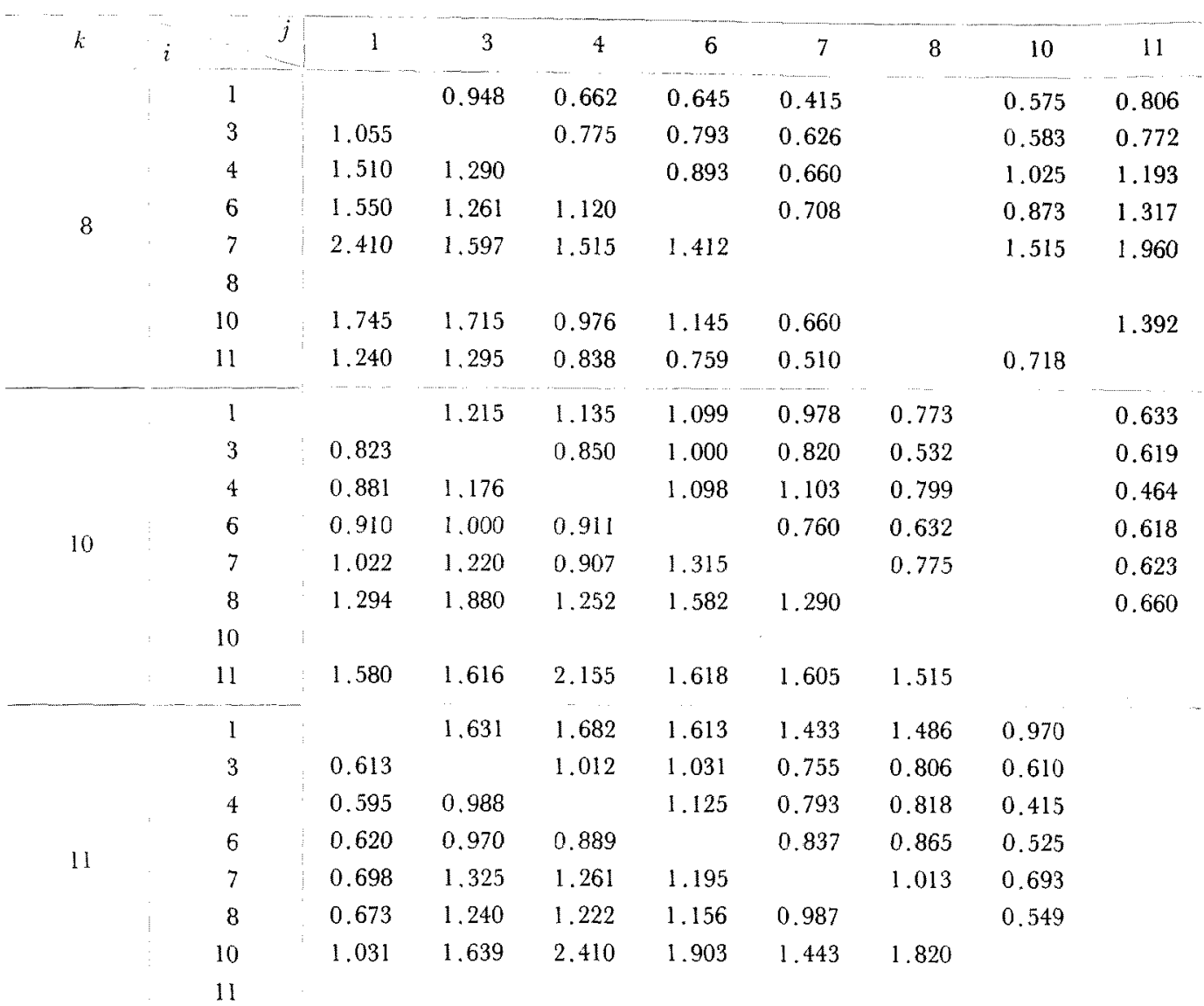

$\dagger$ The entry ${ }_{k} x_{i j}$, represents $d_{j k} / d_{i k}$, where $d_{j k}$ is the distance between No. $j$. figure and No. $k$. figure.

cardboards on which figures were drawn, were presented on the table. Each of them was called $i, j$ and $k$ respectively (left was $i$, middle was $j$ and right was $k$ ). $S$ was requested to estimate similarity between figures in terms of distance. Let $d_{i j}$ represent the judged distance between figures $i$ and $j, S$ was required to estimate $d_{j k}$ when $d_{i j}$ was 1.00. Let ${ }_{j} x_{i k}$ represent the ratio $\left(d_{j k} / d_{i j}\right)$. The task of $S$ was to estimate ${ }_{j} x_{i k}$.

There are 56 triads, with 8 figures $\left.{ }_{8} \mathrm{C}_{3}=56\right)$. In each triad, 6 ways of arrangements of cardboards are possible $\left(_{3} \mathrm{P}_{3}=6\right)$. Therefore a total of 336 arrangements are possible. Each $S$ estimated $x$ twice for all of the arrangements. If the difference of these values was large, then 2 more judgments were repeated. The same arrangement was presented at least 6 days after the last judgment.

Results

Mean values of $10 \mathrm{~S}_{\mathrm{s}}$ are shown in Table 8. The judged distances (in ratio scale) calculated by Torgerson's method (1958), are shown in Table 9 . We analysed the similarity (judged distance) according to the method of multidimensional scaling of Torgerson. We got the loading matrix as in Table 10.

These dimensions were named as follows; the first was left (or right) position of the discus, the second was top (or bottom) position, the third was central (or sides) position of the discus on the figure. The fourth was balance of the figure, the last dimension was strength of association to the 
TABLE 9

The similarity between figures resulted from $10 \mathrm{Ss}$ (ratio scale) $d_{i j}$ (Judged distance)

\begin{tabular}{|c|c|c|c|c|c|c|c|c|}
\hline Figure & 1 & 3 & 4 & 6 & 7 & 8 & 10 & 11 \\
\hline 1 & & 0.968 & 1.045 & 1.238 & 1.082 & 1.340 & 1.087 & 0.737 \\
\hline 3 & & & 0.723 & 0.921 & 1.261 & 1.202 & 1.277 & 1.254 \\
\hline 4 & & & & 0.879 & 1.100 & 0.908 & 1.087 & 1.257 \\
\hline 6 & & & & & 0.643 & 0.877 & 1.254 & 1.277 \\
\hline 7 & & & & & & 0.586 & 1.082 & 1.010 \\
\hline 8 & & & & & & & 0.822 & 1.085 \\
\hline 10 & & & & & & & & 0.697 \\
\hline 11 & & & & & & & & \\
\hline
\end{tabular}

TABLE 10

Loading on dimensions of similarity

\begin{tabular}{r|rrrrr}
\hline Figure & \multicolumn{5}{|c}{ Dimension } \\
& \multicolumn{1}{|c}{ I } & II & \multicolumn{1}{c}{ III } & \multicolumn{1}{c}{ IV } & \multicolumn{1}{l}{ V } \\
I & -.492 & .609 & -.416 & -.509 & .630 \\
3 & -.494 & .257 & .342 & .340 & -.251 \\
4 & -.329 & -.329 & .363 & -.280 & .261 \\
6 & -.487 & -.522 & -.384 & .431 & -.555 \\
7 & .441 & -.453 & -.429 & .404 & .459 \\
8 & .420 & -.393 & .240 & .248 & .194 \\
10 & .461 & .324 & .283 & .252 & .226 \\
11 & .567 & .562 & -.373 & -.378 & .524
\end{tabular}

frame of reference. There were two axes in the response figures, crossing at the center of the figure, one was stretched from the top to the bottom, another was stretched from the left to the right. And these axes were the frame of reference of the position of discus.

Now, let us examine whether we can find dimensions, to which RI has linear relationship (see Table 11). Amounts of RI are plotted according to difference of loadings on a dimension, for all of the 5 dimensions as are shown in Fig. 6. We find that only the last dimension (V) shows linear relationship to $\mathrm{RI}$.

This factor is the strength of association to the frame of reference. It can be said that the effect of this factor on RI coincides with the order of the distance on the large circle, in Exp. II.

In order to determine which of the two (dimension $\mathrm{V}$ or distance) is an adequate determining factor of RI, next experiment was carried out.

TABLE 11

The difference of loadings on each dimension

\begin{tabular}{rrrrrrrrr}
\hline \multicolumn{2}{c}{ Figures } & \multicolumn{7}{c}{ Dimension } \\
OL & IL & I & II & III & IV & V & RI \\
6 & 7 & .928 & .069 & .045 & .027 & 1.014 & 3 \\
1 & 3 & .002 & .352 & .758 & .229 & .881 & 4 \\
10 & 6 & .948 & .846 & .667 & .179 & .781 & 6 \\
3 & 10 & .955 & .067 & .059 & .088 & .474 & 8 \\
7 & 1 & .923 & 1.062 & .013 & .913 & .171 & 14
\end{tabular}




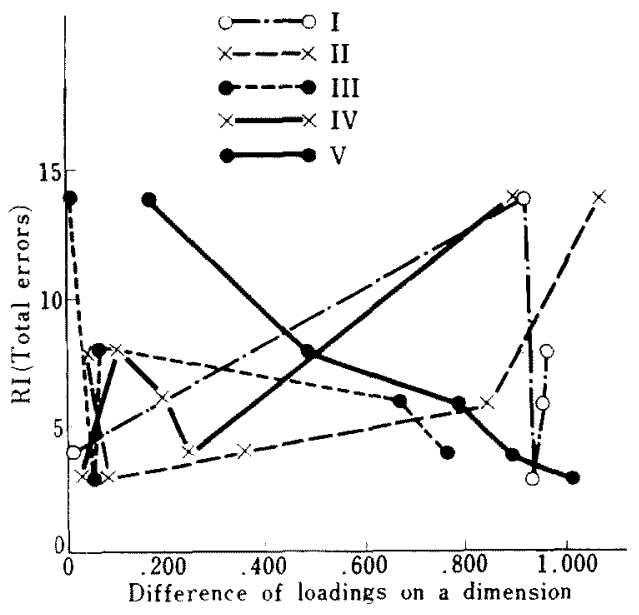

FIG. 6. RI as functions of the difference of loadings on a dimension of similarity.

\section{EXPERIMENT IV}

\section{Method}

Procedure in this experiment was the same as Exp. II. Eight $S$ s were selected from the same group of $S \mathrm{~S}$ in Exp. II (as well as Exp. III). Four sets of $\mathrm{Y}$ items were examined, two of which ( $F$ and $G$ ) maintained 2 unit distance, but differed from one another in difference of loadings on the dimension V. Remaining two sets ( $\mathrm{H}$ and $\mathrm{I}$ ) maintained 4 unit distance, but differed from one another in difference of loadings on the dimension $\mathrm{V}$ (strength of association to the frame of reference), as are shown in Table 12. Four blocks of the blank experiments are shown in Table 13. The design used in Exp. IV is shown in Table 14.

\section{TABLE 12}

The sets of $Y$ items

\begin{tabular}{c|ccc|c}
\hline \multirow{2}{\text{Setof}}{$\begin{array}{c}\text { Response figures } \\
\text { associated with Y }\end{array}$} & $\begin{array}{c}\text { Objective } \\
\text { distance }\end{array}$ & $\begin{array}{c}\text { Difference } \\
\text { of } \\
\text { loadings }\end{array}$ \\
\hline Y items & OL & IL & & \\
\hline F & 8 & 10 & 2 & .032 \\
G & 6 & 4 & 2 & .816 \\
H & 4 & 8 & 4 & .198 \\
I & 10 & 6 & 4 & .781
\end{tabular}

TABLE 13

The blocks for the blank experiments in OL and ILt

\begin{tabular}{|c|c|c|c|c|c|c|c|c|}
\hline \multirow{3}{*}{$\begin{array}{l}\text { Color } \\
\text { for } \\
\text { stimulus } \\
\text { member }\end{array}$} & \multicolumn{8}{|c|}{$\begin{array}{l}\text { Figures for response members } \\
\text { Block for the blank experiments }\end{array}$} \\
\hline & \multicolumn{2}{|c|}{$\zeta$} & \multicolumn{2}{|c|}{$\eta$} & \multicolumn{2}{|c|}{$\theta$} & \multicolumn{2}{|c|}{$\ell$} \\
\hline & OL & IL & & IL & & IL & $\mathrm{DL}$ & IL \\
\hline $\mathrm{R}$ & 6 & 8 & 1 & 5 & 9 & 6 & 5 & 1 \\
\hline $\mathrm{O}$ & 9 & 1 & 5 & 8 & 1 & 9 & 8 & 6 \\
\hline $\mathrm{G}$ & 5 & 9 & 8 & 1 & 6 & 8 & 9 & 5 \\
\hline B & 8 & 6 & 6 & 9 & 5 & 1 & 1 & 8 \\
\hline $\mathrm{V}$ & 1 & 5 & 9 & 6 & 8 & 5 & 6 & 9 \\
\hline
\end{tabular}

+ These lists are added to $Y$ items, $S$ learns 6 items in a list.

TABLE 14

The experimental design in Exp. IV

\begin{tabular}{|c|c|c|c|c|c|}
\hline \multirow{2}{*}{$\begin{array}{c}\text { Order of } \\
\text { experiments }\end{array}$} & \multirow{2}{*}{ Subjects } & \multicolumn{4}{|c|}{ Days of experiments } \\
\hline & & 1 & 2 & 3 & 4 \\
\hline I & 1,5 & $F_{\ell}$ & $\mathrm{G} \zeta$ & $\mathbf{I} \theta$ & $\mathrm{H}_{\gamma}$ \\
\hline II & 2,6 & $\mathbf{I} \zeta$ & $\mathrm{H}_{\epsilon}$ & $F_{\eta}$ & $\mathrm{G} \theta$ \\
\hline III & 3,7 & $\mathrm{G} \eta$ & $\mathbf{F} \theta$ & $\mathrm{H} \zeta$ & It \\
\hline IV & 4,8 & $\mathrm{H} \theta$ & $\mathrm{I} \eta$ & $G_{\ell}$ & $F_{\zeta}^{\zeta}$ \\
\hline
\end{tabular}

TABLE 15

RI, number of errors in RLt

\begin{tabular}{|c|c|c|c|c|c|c|c|}
\hline \multirow{2}{*}{ Group } & \multirow{2}{*}{$\begin{array}{c}\text { Order of } \\
\text { experi- } \\
\text { ments }\end{array}$} & \multirow{2}{*}{ Subject } & \multicolumn{4}{|c|}{$\begin{array}{c}\text { Days of } \\
\text { experiments }\end{array}$} & \multirow[t]{2}{*}{ Total } \\
\hline & & & 1 & 2 & 3 & 4 & \\
\hline \multirow{5}{*}{1} & I & 1 & 1 & 1 & 4 & 4 & 10 \\
\hline & II & 2 & 1 & 0 & 1 & 1 & 3 \\
\hline & III & 3 & 0 & 0 & 1 & 0 & 1 \\
\hline & IV & 4 & 2 & 0 & 1 & 4 & 7 \\
\hline & & Total & 4 & 1 & 7 & 9 & 21 \\
\hline \multirow{5}{*}{2} & I & 5 & 1 & 0 & 1 & 1 & 3 \\
\hline & II & 6 & 0 & 1 & 1 & I & 3 \\
\hline & III & 7 & 0 & 2 & 1 & 2 & 5 \\
\hline & IV & 8 & 0 & 0 & 0 & 2 & 2 \\
\hline & & Total & 1 & 3 & 3 & 6 & 13 \\
\hline
\end{tabular}

$\uparrow$ This experiment was carried out according to Table 14 


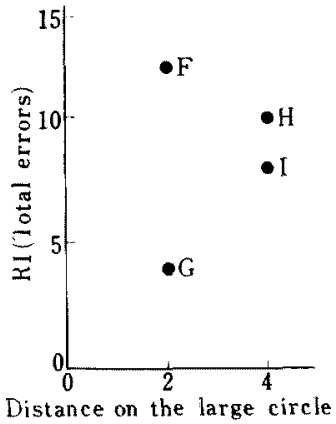

FIG. 7. The amount of RI in two cases of equal distance on the large circle.

\section{Results}

The results are shown in Table 15. The amount of RI of the set $F$ was 12, and $G$ was 4 , in spite of the equality of 2 unit distance. And for the set $\mathrm{H}$ it was 10 , it was 8 for set I, although these sets maintained equal distance of 4 units. The difference between the amounts of RI in $F$ and $G$ is very large in spite of the equality of the objective distance on the large circle, although the difference between amounts in $\mathrm{H}$ and $\mathrm{I}$ is not large as is shown in Fig. 7.

\section{Discussion}

These results obtained in these experiments show that objective distance between disci of response figures is not an adequate determining factor of RI, as the amount of RI cannot well be explained by the distance on the large circle. On the other hand, we find linear relationship between RI and difference of loadings on the dimension $\mathrm{V}$, when the amounts of RI are arranged according to the amounts of differences of loadings on the dimension.

We can predict the amounts of RI in Exp. II by the difference of loadings on the dimension $\mathrm{V}$, based on the results of Exp. IV. The relationship between mean value of RI and similarity of the dimension V, is obtained by the method of least squares. The relation can be written as

$$
R I=-1.0(d V)+1.5
$$

TABLE 16

Predicted amounts of RI in Exp. II

\begin{tabular}{ccc}
\hline $\begin{array}{c}\text { Difference of } \\
\text { loadings } \\
\text { on the dimension } V\end{array}$ & Predicted & Obtained \\
1.014 & 5 & 3 \\
.881 & 6 & 4 \\
.781 & 7 & 6 \\
.474 & 10 & 8 \\
.171 & 13 & 14
\end{tabular}

Where $R I$ represents mean value of $\mathrm{RI}$, and $d V$ represents difference of loadings on the dimension V. Predicted amounts of RI calculated by this equation are compared with the results of Exp. II. It is obvious (sce Table 16) that the amounts of RI in Exp. II fit the predicted well. We can say that the difference of loadings or relative distance on the dimension $\mathrm{V}$ is a determining factor of RI, and that the objective distance between disci on the large circle is not a determining factor. Five sets (pairs of paired-associates in OL and IL) in Exp. II differ in relative distances on the dimension $V$ which coincide with the order of the objective distance. The linear relationship between the amount of RI and the objective distance results from the coincidence. Results of Exp. II and Exp. IV show that the determining factor of RI is the difference of loadings between response figures on the dimension $\mathrm{V}$.

\section{REFERENCES}

Grsson, E.J. 1941 Retroactive inhibition as a function of degree of generalization between tasks. 7. exp. Psychol., 28, 93-115.

Japan Color Reseach Institute 1954 Guide to Color standard. Tokyo: Nippon Shikisaisha.

Osgood, C. E. 1946 Meaningful similarity and interference in learning. 3. exp. Psychol., 36, 277-301.

Osgood, C. E. 1948 An investigation into the cases of retroactive interference. $\mathcal{j}$. exp. Psychol., 38, 132-154. 
OsGoon, C. E. 1949 The similarity paradox in human learning: A resolution. Psychol. Rev., 56, 132-143.
Torgerson, W.S. 1958 Theory and methods of scaling. New York: John Wiley.

(Received April 13, 1968) 